\title{
Hydration Behaviors of Portland Cement with Different Lithologic Stone Powders
}

\author{
Zuqiang Xiong ${ }^{1)}$, Peng Wang ${ }^{1)}$, and Yuli Wang ${ }^{2), *}$
}

(Received January 17, 2014, Accepted July 18, 2014, Published online October 1, 2014)

\begin{abstract}
In this study, influence of different stone powders (SP), including limestone powders (LP), quartzite powders (QP), and granitic powders (GP), on the hydration behaviors of portland cement, for example, setting time, hydration heat, and hydration products, were discussed. The initial and the final setting time both shorten when the content of LP is $5 \%$, however, they are slightly delayed by the other two SPs. The LP has no obvious influence on the arrival time of the first peak in the exothermal curves, and it makes the peak value decrease; the other two SPs postpone the appearance of the first peak, and they also make the peak value decrease. For the second peak, LP shifts the peak position to the left, QP has no effect on this peak position, and GP makes the appearance of this peak delayed by $143 \mathrm{~min}$. Similarly, three kinds of SPs have different influence on the hydration products of portland cement. The LP precipitates the formation of hydrated calcium carbo aluminate, the QP the formation of hydrated garnet, and the GP makes the amount of Tobermorite increase.
\end{abstract}

Keywords: lithology, stone powders (SP), portland cement, hydration product.

\section{Introduction}

SP is by-product from the production of manufactured fine aggregate (MFA), and its size is $-75 \mu \mathrm{m}$, which has the same mineral composition as the mother rock of MFA (Li et al. 2006). Some studies showed that LP was not completely inert, and it could react with $\mathrm{C}_{3} \mathrm{~A}$ and $\mathrm{C}_{4} \mathrm{AF}$ into hydrated calcium carbo aluminate, thereby making the properties of cementbased materials improved (Gutteridge and Dalzeil 1990; Soroka and Stern 1976; Bonavetti et al. 2003; Bonavetti and Irassar 1994; Bonavetti et al. 2001; Poppe and Schutter 2005). Kakali et al. (2000) examined the hydration product of portland cement with $0,10,20$ and $35 \%$ of LP at 28 days, and revealed the reaction mechanism of $\mathrm{C}_{3} \mathrm{~A}$ and $\mathrm{LP}$, which showed that LP imposed great influence on the hydration products because of the formation of calcium carbo aluminate. XRD peaks of $\mathrm{Ca}_{4} \mathrm{Al}_{2} \mathrm{O}_{6} \cdot \mathrm{CO}_{3} \cdot 11 \mathrm{H}_{2} \mathrm{O}$ and $\mathrm{Ca}_{4} \mathrm{~A}$ $1_{2} \mathrm{O}_{6} \cdot\left(\mathrm{CO}_{3}\right)_{0.5}(\mathrm{OH}) \cdot 11.5 \mathrm{H}_{2} \mathrm{O}$ became more obvious as the content of LP increased, and LP quickened the formation of calcium carbo aluminate and slowed down the formation of calcium Sulpho aluminate. Zhou et al. (1996) found that different lithologic SPs could accelerate the hydration of

\footnotetext{
${ }^{1)}$ School of Energy Science and Engineering, Henan Polytechnic University, Jiaozuo 454003, China.

${ }^{2)}$ School of Materials Science and Engineering, Henan Polytechnic University, Jiaozuo 454003, China. *Corresponding Author; E-mail: wangyuli@hpu.edu.cn Copyright (C) The Author(s) 2014. This article is published with open access at Springerlink.com
}

portland cement, and the SP could act as a nuclei and induced the devitrification of the hydration products, therefore increasing the cement hydration reaction rate. Hydrated calcium carbo aluminate was formed and the transformation of ettringite to hydrated calcium sulfo aluminate was restrained when LP was mixed. Kumar et al. (2013a) and Oey et al. (2013) estimated the influence of limestone fillers on reaction and property evolution in cementitious materials with simple methods, and it is concluded that the limestone fillers have accelerations in reactions. Kumar et al. (2013b) made a comparison of intergrinding and blending limestone on reaction and strength evolution in cementitious materials, and the results suggest that intergrinding or blending are both viable strategies to reduce the clinker factors of portland cement.

However, the research focuses on the influence of MFA and LP on the properties of concrete and cements, and the reports of other kinds of MFA and SP are less. The lithology of SP may be different because of its mother rock; therefore, the influences of SP derived from different lithologic rocks on the hydration behaviors of cement were comparatively studied.

\section{Raw Materials and Test Methods}

\subsection{Raw Materials}

The Huaxin P.O52.5 cement was used, whose properties meet the requirement of the Common portland cement (GB175-2007), and its composition was showed in Table 1. The different lithologic SPs were used, including LP, QP, and GP, and their specific surface area was listed in Table 2 and the main chemical composition in Table 3. XRD patterns of the SPs were shown in Fig. 1. 
Table 1 Main mineral composition of the cement (\%).

\begin{tabular}{c|c|c|c|c}
\hline Brand & $\mathrm{C}_{3} \mathrm{~S}$ & $\mathrm{C}_{2} \mathrm{~S}$ & $\mathrm{C}_{3} \mathrm{~A}$ & $\mathrm{C}_{4} \mathrm{AF}$ \\
\hline \hline P.O52.5 & 40.62 & 29.58 & 10.42 & 9.15 \\
\hline
\end{tabular}

Table 2 Specific surface area of the cement and SPs.

\begin{tabular}{c|c|c|c|c}
\hline Raw materials & P.O52.5 & LP & QP & GP \\
\hline \hline $\begin{array}{c}\text { Specific surface area } \\
\left(\mathrm{m}^{2} / \mathrm{kg}\right)\end{array}$ & 438.3 & 369.5 & 336.2 & 330.3 \\
\hline
\end{tabular}

Table 3 Chemical compositions of the cement and SPs.

\begin{tabular}{|c|c|c|c|c|}
\hline & P.052.5 & LP & $\mathrm{QP}$ & GP \\
\hline \multicolumn{5}{|c|}{ "Chemical compositions (\%) } \\
\hline $\mathrm{CaO}$ & 60.68 & 49.08 & 3.06 & 5.46 \\
\hline $\mathrm{SiO}_{2}$ & 21.96 & 5.05 & 59.22 & 16.59 \\
\hline $\mathrm{Al}_{2} \mathrm{O}_{3}$ & 5.86 & 1.62 & 20.39 & 16.59 \\
\hline $\mathrm{Fe}_{2} \mathrm{O}_{3}$ & 3.01 & 0.61 & 9.01 & 5.02 \\
\hline $\mathrm{K}_{2} \mathrm{O}$ & - & 0.52 & - & 0.63 \\
\hline $\mathrm{Na}_{2} \mathrm{O}$ & - & 0.04 & - & - \\
\hline $\mathrm{MgO}$ & 2.91 & 1.59 & 3.03 & 2.62 \\
\hline $\mathrm{TiO}_{2}$ & - & 0.07 & - & - \\
\hline $\mathrm{MnO}$ & - & 0.09 & - & - \\
\hline $\mathrm{P}_{2} \mathrm{O}_{5}$ & - & 0.16 & - & - \\
\hline $\mathrm{SO}_{3}$ & 2.38 & 0.22 & - & - \\
\hline I.L. & 2.58 & 40.88 & 4.86 & 4.84 \\
\hline Total & 99.38 & 99.93 & 99.57 & 99.39 \\
\hline
\end{tabular}

From the above XRD patterns, it can be concluded that LP is mainly composed of calcites and Dolomites, QP is composed of quartz, and GP is composed of quartz and fairchildite.

\subsection{Test Methods}

The normal consistency and the setting time were tested according to the Test methods for water requirement of normal consistency, setting time and soundness of the Portland cement (GB/T1346-2011), and the specific surface area test was carried out according to the Testing method for specific surface of cement-Blaine method (GB/T 8074-2008). The exothermal curves were achieved using the Heat conduction calorimetry and SETARAM hydration exothermal analyzer. The total powder quality of cement and SP is $500 \mathrm{mg}$ for any sample, water to powder ratio is $1: 1$, and the exothermal curves were continuously recorded for $48 \mathrm{~h}$.

\section{Results and Discussion}

\subsection{Influence of SPs on the Standard Viscosity and Setting Time}

The total quality of the sample is fixed at $500 \mathrm{~g}$ and the contents of SPs are $0,5,10,15$, and $20 \%$ in the samples, respectively. The influences of SPs on the initial, the final setting time, and the normal consistency of cement were tested. It can be concluded from Table 4 that the normal consistency of the mixture paste gradually increased as the content of LP increases, the influence regularities of QP and GP are the same as the LP, and they all make the water requirement increase.

The initial setting time shortens by $20 \mathrm{~min}$ when the content of LP is $5 \%$, and the initial setting time is the same as the control without LP when the content of LP is equal to or greater than $10 \%$. The initial setting time does not change when the content of QP is 5\%, and it increases by 3-10 min when the content of QP continuously increases. The initial setting time increases by $17 \mathrm{~min}$ when the content of GP is $5 \%$, and it delays by 16-24 min when the content is greater than $5 \%$.

As shown in Table 4, SPs have similar influence regularity on the final setting time. The final setting time shortens by 13 min when the LP is $5 \%$, the final setting time is the same as the control when the content of LP is $10-15 \%$, and it increases by $10 \mathrm{~min}$ when the content of LP is greater than $15 \%$. For QP, the final setting time is the same as the control when the content is $5 \%$, and it delays by $3-12$ min when the content is greater than $5 \%$. The final setting time increases by $3-15$ min when GP is mixed at any content. 


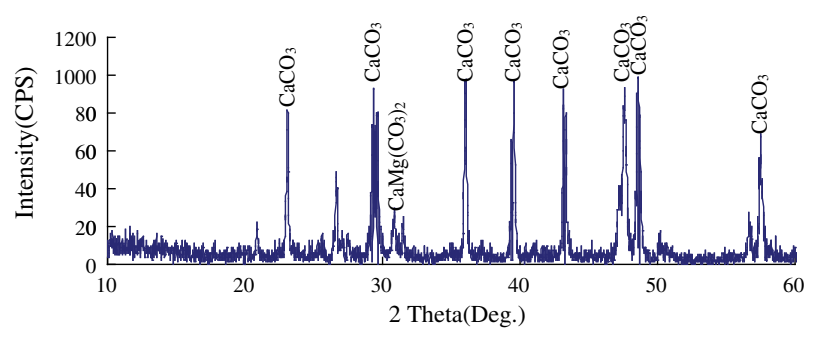

(a) LP

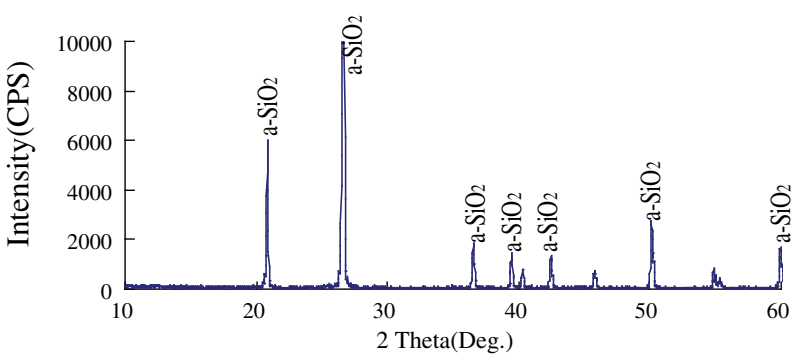

(b) QP

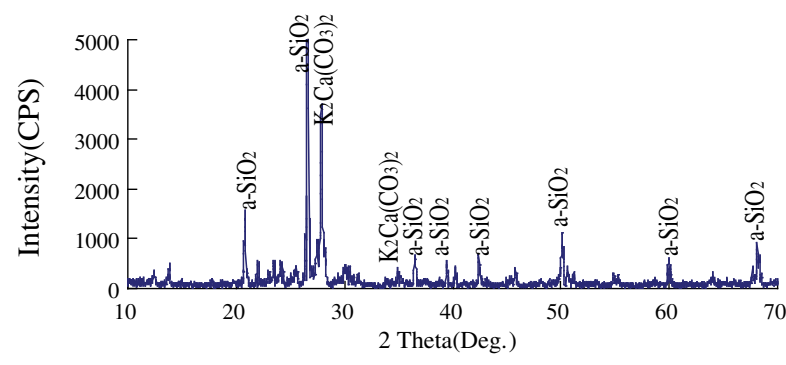

(c) GP

Fig. 1 XRD patterns of the SPs.
In conclusion, the three kinds of SP all make the normal consistency of cement increase; the initial and final setting times delay when the content of LP is $5 \%$, and they have no great change when the content increases; the initial and final setting times slightly prolongs when QP or GP is mixed.

\subsection{Influence of SP on the Hydration Thermal of Cement}

The mix proportion was shown in Table 5, and the continuous exothermal curves of the hydrating samples for $48 \mathrm{~h}$ were shown in Fig. 2. Figure $2 \mathrm{a}$ shows the exothermal curves of 48 h, Fig. 2b, c are the enlarged figures of the first peak and the second peak, which is to be easily observed. As is shown in Fig. 2b, the first exothermal peaks of the $\mathrm{CN}$, CL1, CL2, CQ and CG samples appear at 200.5, 200.5, 200.5 , 236.6, and $272.7 \mathrm{~s}$, respectively. The LP has no influences on the arrival of the first peak whether it was internally or externally mixed, and the appearance of the first exothermal peak delays by 36.1 and $72.2 \mathrm{~s}$ when the QP and the GP were mixed, respectively

The first exothermal peak of the cement hydration is caused by the formation of Ettringite (Runzhang 1996). It can be concluded from Fig. $2 b$ that the LP has no influence on the arrival time of the first peak, however, the peak area decreases, which may be ascribed to the less cement; the arrival time of the first peak delays when the GP and the QP were mixed, which indicates that they postpone the formation of Ettringite, and the peak areas decrease, also. The first peak values of the $\mathrm{CN}$, the CL1, the CL2, the CQ, and the CG are 16.34, 12.76, $12.37,11.97$, and $11.89 \mathrm{~mW}$, accordingly, which shows that the first value decreases when SP is mixed.

Table 4 Influence of SPs on the setting time.

\begin{tabular}{|c|c|c|c|c|c|c|c|}
\hline \multirow[t]{2}{*}{ SP } & \multirow[t]{2}{*}{ Performance } & \multicolumn{6}{|c|}{ Percentage content $(\%)$} \\
\hline & & 0 & 5 & 10 & 15 & 20 & 30 \\
\hline \multirow[t]{3}{*}{ LP } & $\begin{array}{c}\text { Initial setting } \\
\text { time (min) }\end{array}$ & 176 & 158 & 178 & 176 & 177 & 176 \\
\hline & $\begin{array}{c}\text { Final setting time } \\
\text { (min) }\end{array}$ & 223 & 210 & 226 & 226 & 233 & 235 \\
\hline & $\begin{array}{c}\text { Normal } \\
\text { consistency (\%) }\end{array}$ & 25.8 & 25.8 & 26.0 & 26.4 & 26.6 & 27.2 \\
\hline \multirow[t]{3}{*}{ QP } & $\begin{array}{c}\text { Initial setting } \\
\text { time (min) }\end{array}$ & 175 & 174 & 185 & 185 & 178 & 180 \\
\hline & $\begin{array}{c}\text { Final setting time } \\
(\mathrm{min})\end{array}$ & 238 & 238 & 247 & 250 & 241 & 238 \\
\hline & $\begin{array}{c}\text { Normal } \\
\text { consistency (\%) }\end{array}$ & 25.8 & 26.0 & 26.4 & 26.6 & 26.8 & 27.4 \\
\hline \multirow[t]{3}{*}{ GP } & $\begin{array}{c}\text { Initial setting } \\
\text { time (min) }\end{array}$ & 175 & 192 & 199 & 191 & 194 & 190 \\
\hline & $\mid \begin{array}{c}\text { Final setting time } \\
(\mathrm{min})\end{array}$ & 220 & 225 & 229 & 223 & 229 & 235 \\
\hline & $\begin{array}{c}\text { Normal } \\
\text { consistency (\%) }\end{array}$ & 25.8 & 26.0 & 26.2 & 26.6 & 26.8 & 27.4 \\
\hline
\end{tabular}


Table 5 Mix proportion.

\begin{tabular}{c|c|c|c|c}
\hline \multirow{2}{*}{ No } & \multicolumn{3}{|c|}{ Raw materials (mg) } & \multirow{2}{*}{ Remarks } \\
\cline { 2 - 5 } & Cement & SP & Water & Sample for reference \\
\hline \hline CN & 500 & 0 & 500 & $\begin{array}{c}20 \% \text { of LP was internally } \\
\text { mixed }\end{array}$ \\
\hline CL1 & 400 & 100 & 500 & $\begin{array}{c}20 \% \text { of LP was externally } \\
\text { mixed }\end{array}$ \\
\hline CQ & 400 & 100 & 400 & $\begin{array}{c}20 \% \text { of QP was externally } \\
\text { mixed }\end{array}$ \\
\hline CG & 400 & 100 & 400 & $\begin{array}{c}20 \% \text { of GP was externally } \\
\text { mixed }\end{array}$ \\
\hline
\end{tabular}

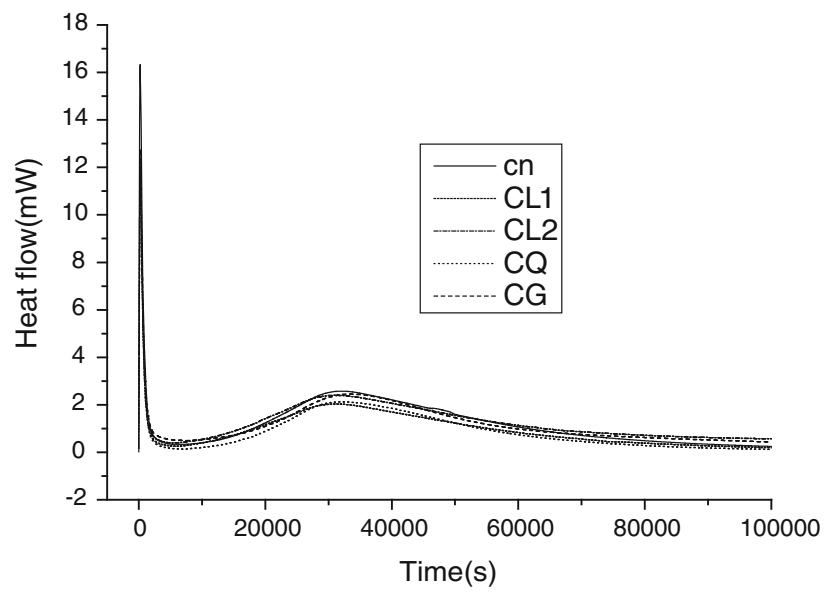

(a) Exothermal curve

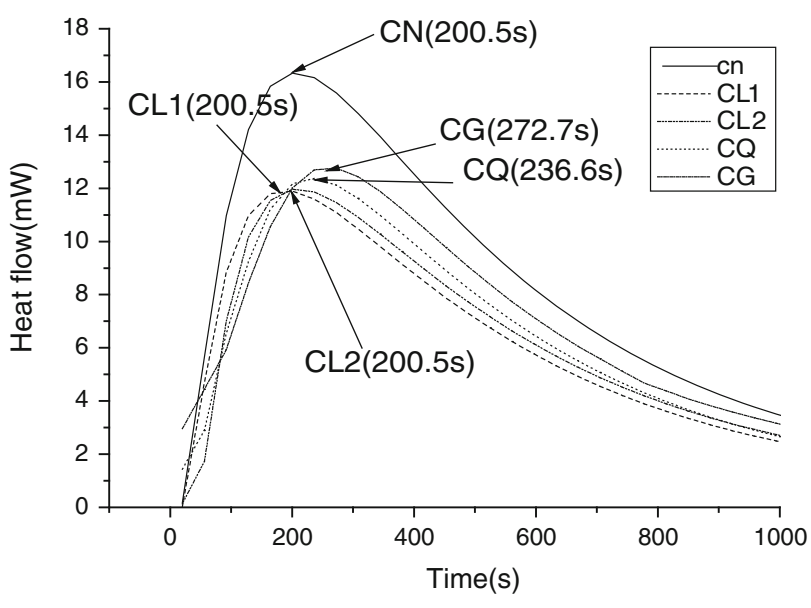

(b) The first exothermal peak enlarged

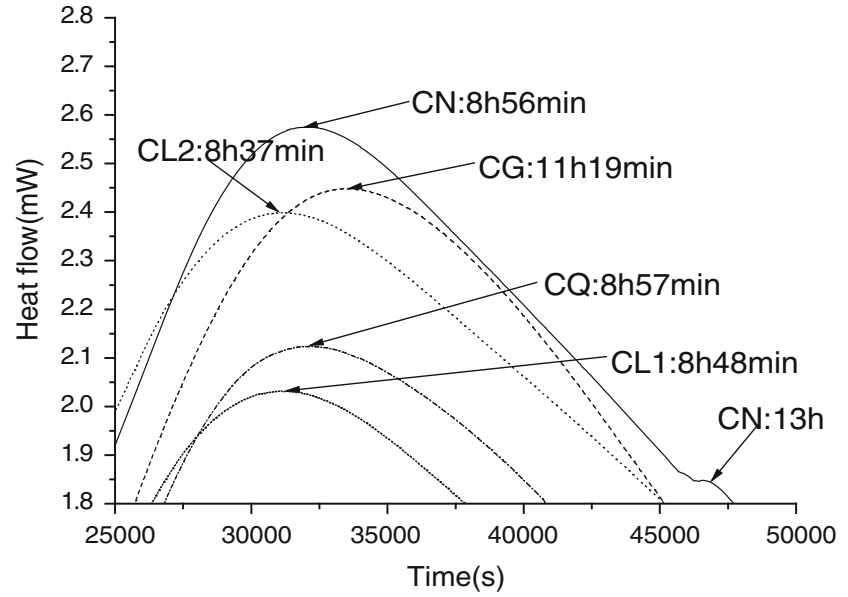

(c) The second exothermal peak enlarged

Fig. 2 Exothermal curves of cement with SP. a Exothermal curve. b The first exothermal peak enlarged. c The second exothermal peak enlarged.

The second peak in the exothermal curve is formed because of the hydration of $\mathrm{C}_{3} \mathrm{~S}$ (Runzhang 1996). It can be seen from Fig. $2 \mathrm{c}$ that the arrival time of the second peaks are 516, 528, 536, 537, and $679 \mathrm{~min}$, respectively. The LP shifts the peak position to the left, which shows that the hydration of cement is accelerated by the LP. However, the appearances of the second peaks delays by 1 and $143 \mathrm{~min}$ by the QP and the GP, respectively; this shows that the QP has no obvious effect on the hydration of $\mathrm{C}_{3} \mathrm{~S}$ and the GP has obvious effect. The values of the second peak are 2.48, 2.45, $2.40,2.12$, and $2.03 \mathrm{~mW}$, according to the $\mathrm{CN}$, the $\mathrm{CG}$, the CL2, the CQ and the CL1. It can be concluded that the SPs, especially for the QP and the GP, decreases the concentration of hydration heat from the two exothermal peaks. 


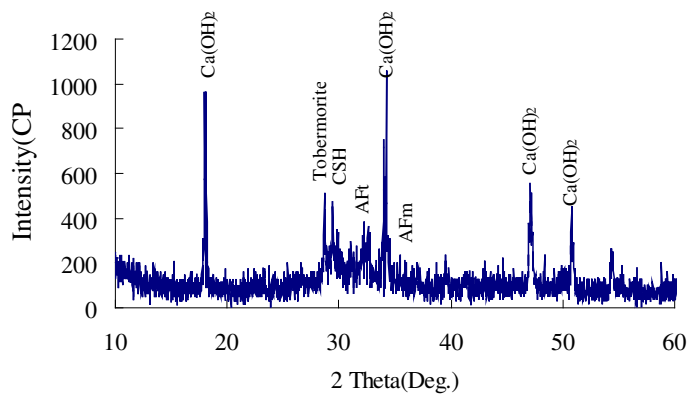

(a) P.O52.5 without SP

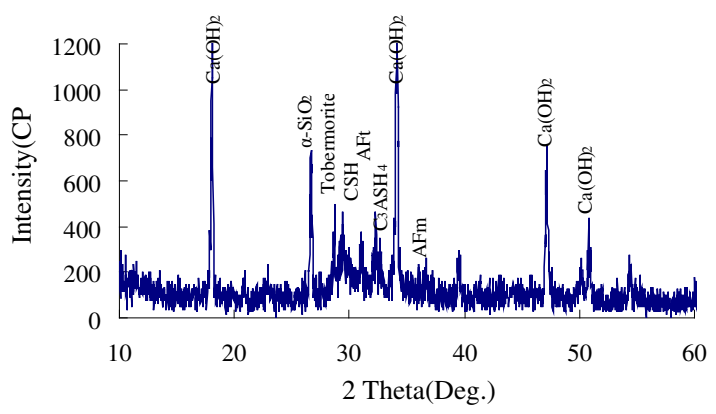

(c) P.O52.5 cement with QP

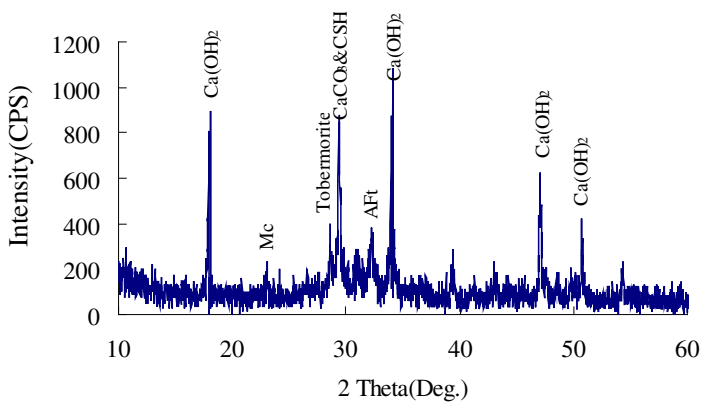

(b) P.O52.5 with LP

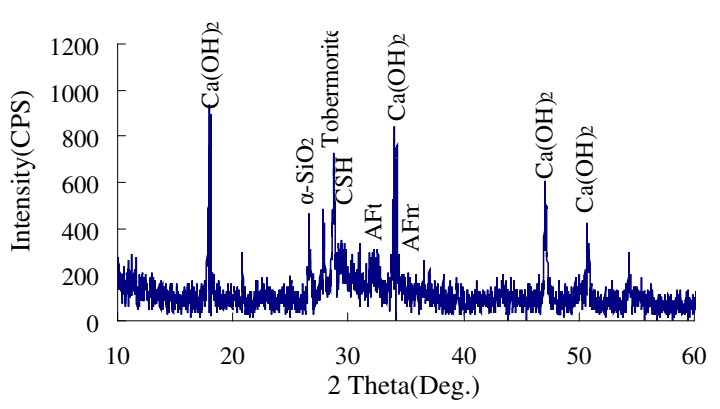

(d) P.O52.5 with GP

Fig. 3 XRD patterns of the samples. a P.052.5 without SP. b P.052.5 with LP. c P.052.5 cement with QP. d P.052.5 with GP.

There is another small peak appeared at $780 \mathrm{~min}$ in the exothermal curve of the $\mathrm{CN}$ sample in Fig. 2c, however, the peak cannot be observed in the other samples with SPs. The peak is formed by the transformation of AFt to AFm, therefore, the transformation is prevented by the SPs.

\subsection{Influence of SPs on the Hydration Products}

Different samples were prepared to study the influence of SPs on the hydration products of cement, and $220 \mathrm{~g}$ of water and $500 \mathrm{~g}$ of powders were used in every sample. The first sample is cement of $100 \%$, and the other three samples are that the cement is replaced by $10 \%$ by quality by the LP, the QP, and the GP, respectively. The XRD patterns are shown in Fig. 3.

It can be concluded through comparing Fig. $3 \mathrm{a}, \mathrm{b}$ that the $\mathrm{LP}$ induces the formation of $\mathrm{C}_{3} \mathrm{~A} \cdot \mathrm{CaCO}_{3} \cdot 11 \mathrm{H}_{2} \mathrm{O}$, which is shown at $2 \theta$ of $23^{\circ}$ in Fig. $3 \mathrm{~b}$ and the influence of the LP on the hydration of tricalcium silicate is unclear because of the peak overlapping of hydrated calcium silicate and calcium carbonate. The QP induces the appearance of peaks of $\mathrm{C}_{3} \mathrm{ASH}_{4}$ in Fig. 3c, which indicates the formation of a new phase. It can be seen from Fig. $3 d$ that the peak intensity of Tobermorite is strengthened by the GP, which shows that the amount of Tobermorite is more when the GP is mixed.

\section{Conclusions}

The influences of the SPs on basic performances and hydration of portland cement were comparatively studied, and the following conclusions are as follow.
(1) The normal consistency increases as the content of SP increases. The initial setting time and final setting time both shortens when the content of LP is $5 \%$, and they slightly delays because of the QP and the GP.

(2) The LP has no effect on the arrival time of the first peak in the exothermal curve, however, the peak value decreases. The arrival time of the first peak postpones and the peak value also decreases because of the GP and the QP. The second peak shifts it position to the left when the LP is mixed, the QP has no obvious influence on the peak position, however, the peak is delayed by $143 \mathrm{~min}$ by the GP.

(3) The LP induces the formation of hydrated calcium carboaluminate, the QP the formation of hydrated garnet, and the GP makes the amount of Tobermorite greater.

\section{Acknowledgments}

This research is funded by the National Natural Science Foundation of China (No. 51274088 and No. 50908076) and Major Scientific Projects of Shanxi Province (No. 20121101002).

\section{Open Access}

This article is distributed under the terms of the Creative Commons Attribution License which permits any use, distribution, and reproduction in any medium, provided the original author(s) and the source are credited. 


\section{References}

Bonavetti, V., Donza, H., Menéndez, G., Cabrera, O., \& Irassar, E. F. (2003). Limestone filler cement in low w/c concrete: A rational use of energy. Cement and Concrete Research, 33(6), 865-871.

Bonavetti, V. L., \& Irassar, E. F. (1994). The effect of stone dust content in sand. Cement and Concrete Research, 24(3), 580-590.

Bonavetti, V. L., Rahhal, V. F., \& Irassar, E. F. (2001). Studies on the carboaluminate formation in limestone filler-blended cements. Cement and Concrete Research, 31, 853-859.

Gutteridge, W. A., \& Dalziel, J. A. (1990). Filler cement: The effect of the secondary component on the hydration of Portland cement: Part I. A fine non-hydraulic filler. Cement and Concrete Research, 20(5), 778-782.

Kakali, G., Tsivilis, S., Aggeli, E., \& Bati, M. (2000). Hydration products of $\mathrm{C}_{3} \mathrm{~A}, \mathrm{C}_{3} \mathrm{~S}$ and portland cement in the presence of $\mathrm{CaCO}_{3}$. Cement and Concrete Research, 30, 1073-1077.

Kumar, A., Oey, T., Kim, S., Thomas, D., Badran, S., Li, J., et al. (2013a). Simple methods to estimate the influence of limestone fillers on reaction and property evolution in cementitious materials. Cement \& Concrete Composites, 42, 20-29.

Kumar, A., Oey, T., Falla, G. P., Henkensiefken, R., Neithalath, N., \& Sant, G. (2013b). A comparison of intergrinding and blending limestone on reaction and strength evolution in cementitious materials. Construction and Building Materials, 43, 428-435.

Li, B. X., Zhou, M.-K., Tian, J.-P., \& Hu, X.-M. (2006). Effect of stone dust and fly ash on properties of C60 high performance concrete containing manufactured sand. Journal of Building Materials, 9(4), 381-387 (in Chinese).

Oey, T., Kumar, A., Bullard, J. W., \& Neithalath, N. (2013). The filler effect: The influence of filler content and surface area on cementitious reaction rates. Journal of the American Ceramic Society, 96(6), 1987-1990.

Poppe, A.-M., \& Schutter, G. D. (2005). Cement hydration in the presence of high filler contents. Cement and Concrete Research, 35(12), 2290-2299.

Runzhang, Y. (1996). Bonding materials science (in China). Wuhan, China: Wuhan University of Technology Press.

Soroka, I., \& Stern, N. (1976). Calcareous fillers and the compressive strength of portland cement. Cement and Concrete Research, 6(3), 367-376.

Zhou, M., Peng, S., Xu, J., \& Zhu, C. (1996). Effect of stone powder on stone chippings concrete. Journal of Wuhan University of Technology (Materials Sciences Edition), 11(4), 29-34 (in Chinese). 